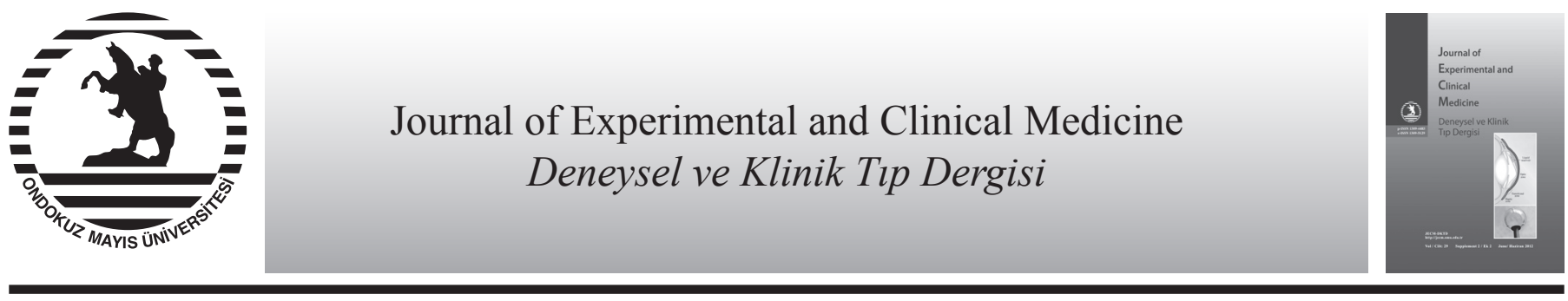

Olgu Sunumu / Case Report

doi: $10.5835 /$ jecm.omu.29.s2.010

\title{
Lazer işaretleyiciye bağlı makula yanığı
}

\section{Macular burn associated with exposure of pointer laser}

Deniz Turgut Çoban**, Yüksel Süllǘb

${ }^{a}$ Gazi Devlet Hastanesi, Göz Hastalıkları Bölümü, Samsun, Türkiye

${ }^{b}$ Ondokuz Mayıs Üniversitei, Tıp Fakültesi, Göz Hastallkları Anabilim Dalı, Samsun, Türkiye

\begin{tabular}{|c|c|}
\hline MAKALE BİLGILERİ & ÖZET \\
\hline Mak & \multirow{4}{*}{$\begin{array}{l}\text { Lazer işaretleyicinin lazerine maruz kalma sonucu makula yanı̆̆ gelişen hastanın sunu- } \\
\text { mu amaçlanmıştır. Yirmi beş yaşında erkek hastanın sağ gözü, birkaç saniye lazer işaret- } \\
\text { leyicinin lazerine maruz kalmıştır. Hastanın muayenesinde görme keskinliğinin tam, ön } \\
\text { segment bulgularının doğal fakat santral görme alanı alt kısımda şekillerde kırılma ve } \\
\text { eğilme gibi görsel semptomların olduğu tespit edilmiştir. Arka segment muayenesinde, } \\
\text { foveada lazere bağlı sarı yanık görülmüştür. Tedavisinde oral ve topikal steroid, topikal } \\
\text { karbonik anhidraz inhibitörü verilerek takibe alınmış, sonrasında hastanın semptomlar1- } \\
\text { nın tam olarak düzeldiği gözlenmiştir. } \\
\text { J. Exp. Clin. Med., 2012; 29:S97-S98 }\end{array}$} \\
\hline Jeliş & \\
\hline Kabul & \\
\hline $\begin{array}{l}\text { Yazışma Adresi: } \\
\text { eniz Turgut Çoban } \\
\text { razi Devlet Hastanesi, }\end{array}$ & \\
\hline
\end{tabular}

e-mail: turgutcoban@yahoo.com

\section{Anahtar Kelimeler:}

Lazer işaretleyici

Makula yanığ 1

Görme keskinliği

\section{Keywords:}

Laser pointer

Macular burn

Visual acuity

\begin{abstract}
It was aimed to present a case of macular burn associated with exposure of pointer laser in the study. Twenty five years old male patient had exposed laser pointer beam to his right eye for a few seconds. Eye examination disclosed his vision was intact except lower central disturbances like refraction and bending errors and natural anterior segment findings. Posterior segment examination showed laser-induced yellow burn on the fovea. The patient was treated with topical carbonic anhydrase inhibitor, oral and topical steroids and followed up. It was observed that vision of the patient resolved completely at the end of follow up period.

J. Exp. Clin. Med., 2012; 29:S97-S98
\end{abstract}

\section{Giriş}

Lazer, 1şı̆̆ın polarize ve monokromatik uyumlu bir 1ş1nıdır. Lazer işaretleyiciler düşük enerjili ışık kaynakları olup noniyonize radyasyon yayarlar (Sethi ve ark., 1999). Elde taşınabilen lazer işaretleyiciler ders salonlarında yaygın olarak kullanılmakta, zararsız ve güvenli olduğu düşünülmektedir. Bununla birlikte ciddi göz hasarına neden olabilirler (Wyrsch ve ark., 2010). Bu amaçla çalışmada lazer işaretleyicinin 1şınına maruz kalma sonrası makula yanığı gelişen 25 yaşında bir erkek hastanın sunulması amaçlanmıştır.

\section{Vaka}

Yirmi beş yaşında erkek hastanın sağ gözü birkaç saniye lazer işaretleyicinin ışınına maruz kalmıştır (Şek. 1). Hasta maruz kalmanın hemen ardından santral görme alanının bulanık ve düzensiz olduğunu fark ederek kliniğimize başvurmuştur. Hastanın muayenesinde görmesinin tam ve ön segment bulgularının doğal olduğu tespit edilmiştir. Arka segment muayenesinde lazere bağlı foveada sarı yanık görülmüştür (Şek. 2). Santral görme alanını değerlendirmek için yapılan görme alanı testinde görme alanının doğal sınırlarda bulunduğu tespit edilmiştir. Hasta Amsler grid kartı ile değerlendirildiğinde ise santraldeki çizgilerin büküldüğünü ve düzensiz görüldüğünü belirtmiştir. Hastanın, Amsler grid kartı üzerine çizim yapması sağlanarak oluşan defekt değerlendirilmiştir. Makula optical coherens tomography (OCT) ile de görüntülenmiş̧tir. Hastaya oral ve topikal steroid, topikal karbonik anhidraz inhibitörü verildi ve takibe alındı. Kontrollerde görsel bulguları düzelen hasta fundus resmi ve OCT ile takip edildi. Takip sonrasında hastanın görmesinin ve semptomlarının tam olarak düzeldiği gözlendi.

\section{Tartıșma}

Lazerler güçlerine göre sınıf 1, 2, 3a, 3b ve 4 olarak s1nıflandırılır. Gözde hasar oluşturabilenler sınıf $3 b$ ve 4 olup, lazer güçleri 2,5mW/ $\mathrm{cm}^{2}$ ' nin üzerindedir (Adjudua ve Mello, 
2007). Hastamızın maruz kaldığı lazer de sınıf 3 b olup retinada sarı yanık alanı oluşturmuştur.

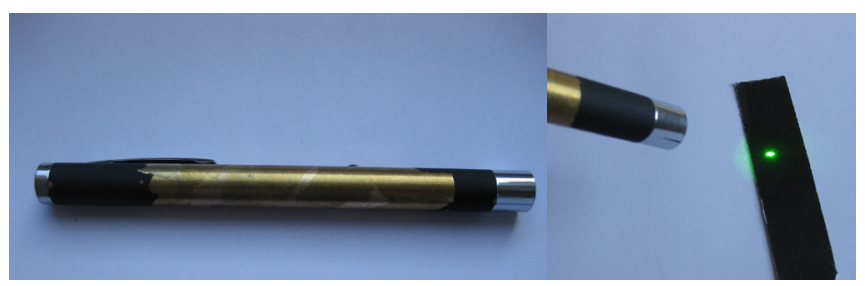

Şek. 1. Hastanın maruz kaldığı lazer işaretleyici

Lazer işaretleyicinin ışınına maruz kalan kişilerde retina hasarı oluşması lazerin gücü, dalga boyu, temas süresi ve pupil büyüklüğü gibi faktörler ile doğru orantılıdır. Lazer maruziyeti retina pigment epitelindeki hafif hasar nadir olmakla birlikte fotomekanik, termal ve fotokimyasal olaylar ile olabilir. Retina pigment epiteli akut fotokoagulasyon hasarı sonrası beyaz görülür. Hastaların değerlendirilmesinde semptomlar göz önüne alınır (Ajudua ve Mello, 2007; Ziahosseini ve ark., 2010).

Lazer sinıf 1, 2 veya 3a'ya maruz kalanlar, asemptomatik ya da geçici semptomatik olabilirler. Ancak bu hastalarda retinada hasar oluşmaz, eğer varsa başka bir neden araşt1rılmalıdır. Lazer sınıf 3b veya 4'e maruz kalanlarda görme keskinliğinde azalma, retinal bulgu ve skotom gibi semptomlardan herhangi biri varsa tam retina muayenesi yapılmalıdır (Adjudua ve Mello, 2007). Bizim hastamizda da retinal bulgu ve skotom semptomları olduğu için tam retina muayenesi ve renkli fundus resmi, görme alanı, Amsler grid karta skotom tespiti ve OCT yapıldı.

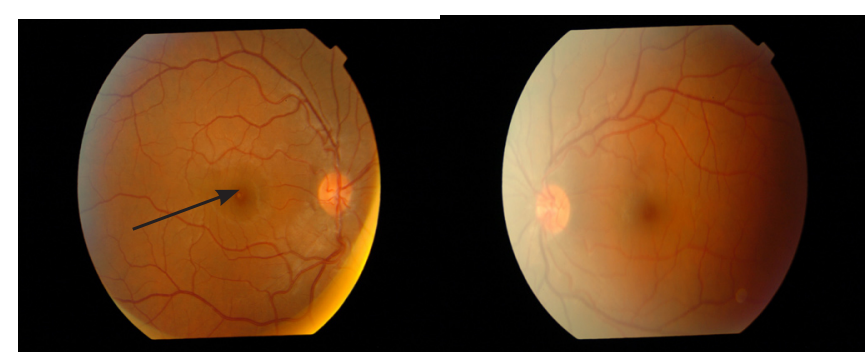

Şek. 2. Lazer işaretleyiciye bağlı makula yanığı (Sağ gözde).

Hastaların semptom ve bulguları genellikle geçicidir. Nadiren de retina ve koroidde hasar ve buna bağlı yıllar sonra idiopatik koroidal neovaskülarizasyon sonucu görme kaybı olabilir (Wyrsch ve ark., 2010). Bizim vakamızda merkezi görme alanında bulanıklık ve retinada yanık mevcuttu ve görme keskinliğinde azalma yoktu. Dört hafta sonraki kontrolde semptom ve bulguların düzeldiği tespit edildi. Hastanın bir yıl sonraki kontrolünde herhangi semptom ve bulgu yoktu.

Lazer işaretleyicilerin, çoğu kullanıcı tarafından zararsız olduğu düşünülmektedir. Lazer gücü $1 \mathrm{~mW}$ olan veya sınıf 1-2 olan grubun kullanılması, üzerinde uyarı bulunması ve göz temasından kaçınılması önemlidir.

\section{KAYNAKLAR}

Adjudua, S., Mello, M.J., 2007. Shedding some light on laser pointer eye injuries. Pediatric Emerg. Care. 23, 669-672.

Marshall, J., 1998. The safety of laser pointers: myths and realities. Br. J. Ophthalmol. 82, 1335-1338.

Sethi, C.S., Grey, R.H.B., Hart, C.D., 1999. Laser pointers revisited: a survey of 14 patients attending casualty at the Bristol Eye Hospital. Br. J. Ophthalmol. 83, 1164-1167.

Wyrsch, S., Baenninger, P.B., Schmid, M.K., 2010. Retinal injuries from a handheld laser pointer. N. Engl. J. Med. 363, $1089-1091$.

Ziahosseini, K., Doris, J.P., Turner, G.S., 2010. Laser eye injuries: Maculopathy from handheld green diode laser pointer. B.M.J 340 , c2982. 